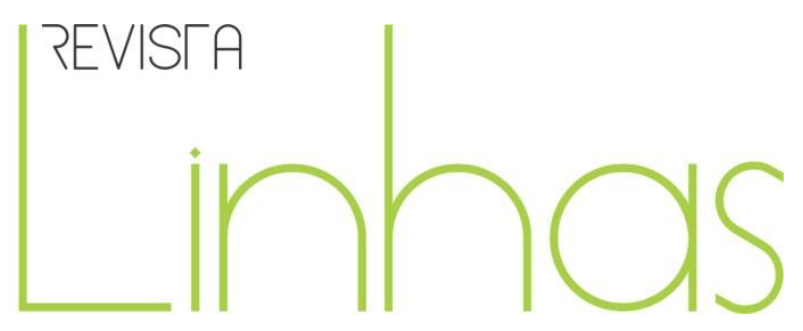

\title{
Matrizes históricas da inspeção escolar no Brasil: mecanismo de controle do trabalho docente em Alagoas nos Oitocentos
}

\begin{abstract}
Resumo
Neste artigo encontram-se os resultados de uma pesquisa sobre as matrizes históricas da inspeção escolar no Brasil, e, também, em Alagoas (1840/1889). O estudo alicerçou-se nas ideias de Gondra e Schuler (2008), Veiga (2007), Bloch (2001), Verçosa (2001), Moacyr Primitivo (1939) e Costa (1931). A partir da investigação em fontes primárias no Arquivo Público de Alagoas, têm-se as conclusões: 1) em Alagoas os inspetores fiscalizavam as escolas e prestavam contas ao Inspetor Geral de Estudos; 2) os professores informavam sobre o funcionamento das aulas, do material didático, da frequência escolar e do aproveitamento da aprendizagem; 3) o inspetor escolar foi o responsável pela articulação entre os professores e o Inspetor Geral de estudos. O controle realizado pela Inspeção Escolar delineou traços da educação de Alagoas no Império.
\end{abstract}

Palavras-chave: Inspeção Escolar. Império. Educação Escolarizada. Professores.
Elione Maria Nogueira Diógenes Universidade Federal de Alagoas - UFAL - Alagoas/Brasil elionend@uol.com.br

\section{Nezilda do Nascimento Silva Pauferro}

Conselho Estadual de Educação de Alagoas - Alagoas/Brasil nezildapauferro@gmail.com

\section{Para citar este artigo:}

DIÓGENES, Elione Maria Nogueira; PAUFERRO, Nezilda do Nascimento Silva. Matrizes históricas da inspeção escolar no Brasil: mecanismo de controle do trabalho docente em Alagoas nos Oitocentos. Revista Linhas. Florianópolis, v. 18, n. 36, p. 121-151, jan./abr. 2017. 


\title{
Historical matrices of school inspection in Brazil: control mechanism of the teaching work in Alagoas in the Eight Hundred
}

\begin{abstract}
In this article, we find the results of a research on the historical matrices of the school inspection in Brazil, and also in Alagoas (1840/1889). The study has its foundations on the ideas of Gondra and Schuler (2008), Veiga (2007), Bloch (2001), Verçosa (2001), Moacyr Primevitivo (1939) and Costa (1931). Based on the research in primary sources in the Public Archives of Alagoas, the conclusions we arrived at, are: 1) in Alagoas, inspectors supervised schools and reported to the Inspector General of Studies; 2) teachers informed on the functioning of classes, educational materials, school attendance and the progress in learning; 3) the school inspector was responsible for the articulation between teachers and the Inspector General of Studies. The control carried out by the School Inspection draw an outline of the Education in Alagoas formal school during the period of the Empire.

Keywords: School Inspection. Empire. School Education. Teachers.
\end{abstract}




\section{Introdução}

Ao constatarmos as diversas lacunas encontradas na historiografia da educação brasileira, especialmente na alagoana, sobre o tema Inspeção Escolar e o pouco registro necessário para compreendê-la na constituição do trabalho docente no Brasil, propusemo-nos a desenvolver este trabalho de pesquisa, com a finalidade de recuperar a memória da Inspeção Escolar em Alagoas. Percebemos a necessidade de recuar no tempo. Pensando assim, as investigações foram direcionadas para a Inspeção Escolar, culminando no tema "As matrizes históricas da Inspeção Escolar no Brasil: mecanismo de controle do trabalho docente em Alagoas (1840 - 1889)".

Esta pesquisa traça, portanto, um recorte cronológico de 1840 até 1889 , o qual se deve ao período em que o Estado, assumindo a administração educacional, criou instrumentos para fiscalizar a ação dos professores, sendo um desses instrumentos a inspeção escolar, além de que, as fontes alagoanas apontaram registros de diferentes protagonistas para a realização da Inspeção Escolar na província aqui em estudo. Outro aspecto importante foi a criação do Liceu Alagoano (1849) e do Curso Normal (1869). Tais elementos assinalam a educação escolar no Segundo Reinado de forma mais institucionalizada, levando-nos a eleger esse período como fundamental para se compreender o desenvolvimento histórico da Inspeção Escolar em Alagoas.

A intenção maior deste texto é compreender como se constituiu a função de inspetor e suas relações com a profissão docente, objetivando entender a inspeção escolar como um instrumento de controle do trabalho do professor - o que supomos, permitirá aos atuais inspetores e demais profissionais da educação ter noção da construção histórica da profissão.

O inspetor, em certos casos, ainda é visto com certo receio, traço historicamente arraigado na profissão. O entendimento equivocado do papel do inspetor escolar parece ser provocado pelo pouco conhecimento histórico sobre esta área de atuação na escolarização brasileira, o que leva, em pleno século XXI, ao desconhecimento da função e do trabalho do inspetor no passado. E faz com que, sem perceber, continue em parte a ser reproduzido o modo de agir que foi se constituindo ao longo do tempo. 
Segundo Ferreira (2001), a palavra inspeção significa revista, fiscalização, carga semântica negativa que expressa a aversão dos professores à figura do inspetor. Diante dessa comprovação, constatamos a necessidade de investigar as matrizes da Inspeção Escolar e suas relações com a profissão docente e, na medida do possível, "desconstruir" as concepções equivocadas atribuídas atualmente a este profissional. Para historiadores como Marc Bloch, o passado só virá à tona caso seja provocado pelo presente. Segundo o autor, "em primeiro lugar, a história não seria mais entendida como uma 'ciência do passado'[...]. Ao contrário, era no jogo entre a importância do presente para a compreensão do passado e vice-versa que a partida era, de fato, jogada" (BLOCH, 2001, p. 7).

Tendo em vista a necessidade de ampliar a compreensão do século XIX, assim como compreender as bases da educação da época, recorremos a alguns teóricos como Costa (1931), Moacyr (1939), Azevedo (1976), Carvalho (1981), Siqueira (2000), Verçosa (2001), Veiga (2007), Gondra e Schueler (2008). Estes autores nos proporcionaram uma visão mais alargada do referido século, tanto com relação aos aspectos mais gerais da época, quanto sobre o movimento de escolarização pública imperial.

Para desenvolver a pesquisa, recorremos às fontes do acervo do Arquivo Público do Estado de Alagoas e do Instituto Histórico e Geográfico de Alagoas, as quais nos forneceram vestígios fundamentais deixados pelos educadores dos séculos passados, o que nos possibilitou o acesso a múltiplas pistas e também despertar para a história da educação alagoana que, até o momento, embora tenhamos tido alguns avanços nos últimos anos, continua carente de novas produções historiográficas da educação.

As fontes primárias, por vezes, têm sido esquecidas pelos pesquisadores alagoanos. Para alguns, os arquivos representam apenas um espaço onde são colocados papéis antigos, documentos que hoje não servem mais. Triste engano! Das fontes primárias, destacamos a riqueza de informação nos relatórios escritos por inspetores que viveram e registraram o andamento da instrução escolar.

Não podemos negar que o trabalho no arquivo é árduo, exige paciência e persistência para investigar o passado cuidando do material deteriorado pela ação do tempo. Porém, é gratificante remexê-lo por conter “[...] informações inestimáveis (muitas vezes inéditas) [...]" (NUNES; CARVALHO, 2005, p. 32). No desenvolvimento da 
pesquisa dialogamos com as fontes, estabelecendo uma relação entre os documentos e o conhecimento literário. Tal diálogo é o que torna vivo o documento, o qual aparentemente parece inerte e esquecido. A cada interrogação que surgia fomos levados a buscar mais informações e cada documento pesquisado nos deu pistas para continuarmos a pesquisa. Com uma leitura mais cuidadosa da fonte é possível desconfiar de suas "verdades" ali postas, ou mesmo levantar desconfianças em torno de uma dada "verdade" teórica. Isso está posto nas palavras de Nunes e Carvalho, quando nos responde sobre as razões pelas quais devemos centrar a discussão em torno de fontes.

Por um motivo simples: os historiadores da educação dependem, nas suas investigações, não apenas das questões formuladas dentro de certas matrizes teóricas, mas também dos materiais históricos com que podem contar. Não fazemos bons trabalhos na área sem respeitar a empiria contra a qual lutamos; e todos já nos deparamos com a dificuldade de recolher fontes impressas e arquivísticas, geralmente lacunares, parceladas e residuais. Apesar dessas dificuldades, é justamente no manuseio crítico das fontes que o pedagogo ganha a distância necessária para olhar de uma nova maneira a pedagogia, tornando-se, pela sua prática e pelo seu projeto, um historiador. (NUNES; CARVALHO, 2005, p. 29)

Foi por meio do ato de vasculhar os documentos encontrados nos arquivos que tomamos gosto pela pesquisa e pelo trabalho do historiador, com base na concepção de tempo em movimento, com o qual podemos dialogar. Como pedagoga e com a prática da inspeção escolar, fomos conhecendo a nossa história e a história dos nossos pares, o caminho que outros percorreram e que ressoa em pleno século XXI. A história da educação, enquanto especialização da História, deve estudar as dimensões pedagógicas sob novos ângulos, estabelecendo arranjos por vezes inusitados, quando articulados com outras áreas, como nos ensina Bloch (2001, p. 21): aprender ““[...] a... pensar menos barato"”.

Entendemos que é necessário continuar a fazer uma crítica vigorosa das fontes, quer seja das lacunas nos documentos, dos acervos, das comparações e cruzamento de informações, quer seja da literatura já construída, assim continuam a nos falar Nunes e Carvalho (2005, p. 35): “Mapear fontes é, portanto, preparar o terreno para uma crítica empírica vigorosa que constitua novos problemas, novos objetos e novas abordagens". 
Esta crítica significa contextualizar a produção do documento, o autor e o vínculo de informação para que, assim, o passado nos chegue de forma generosa (LARA, 2008).

Todo esse trabalho nos despertou um desejo de continuar garimpando informações sobre o tema. Além de tentar desconstruir a visão distorcida dada à inspeção escolar por profissionais da educação que atuam nas instituições de ensino e nas secretarias de educação. Com isto, este trabalho propõe refletir sobre o sistema de vigilância instituído no ensino brasileiro do século XIX, entendendo que essa visão ainda ocorre na atual organização do Estado brasileiro, o qual, no decorrer do século $\mathrm{XX}$, provocou certa burocratização do cargo, tornando-o mais uniforme, diferentemente do que ocorria no Império. Entendemos que recuar no tempo significa compreender o nascedouro desta ação e isso nos ajudará a entendê-la melhor. "O presente bem referenciado e definido dá início ao processo fundamental do ofício do historiador: 'compreender o presente pelo passado' e, correlativamente, 'compreender o passado pelo presente"" (BLOCH, 2001, p. 25).

Nessa perspectiva, um estudo dessa natureza requer uma metodologia pertinente. Assim, a fundamentação teórica e metodológica desta pesquisa apoia-se na historiografia dos Annales ${ }^{1}$ pois, “[...] ao lado do necessário rigor ligado à erudição e à investigação dos mecanismos históricos, existe a 'volúpia de aprender as coisas singulares [...]”" (BLOCH, 2001, p. 19).

Para cada documento surgem várias indagações que possibilitam a transformação deste em fonte e em um diálogo entre as informações garimpadas (bibliográfica / documentais), que nos proporcionam um olhar mais alargado. As fontes nos fornecem indícios, como se fossem um "mosaico” em que vestígios alargados tornam-se generosos para o trabalho. Não se trata de transcrever o que está contido nas fontes, mas analisálas, relacionando-as com eventos mais largos que não estão expostos claramente nos documentos e que nos permitem um entendimento mais consubstanciado dos sujeitos no seu tempo.

\footnotetext{
1 Reunidos em torno da revista Annales, fundada em 1929, um grupo de historiadores produziu uma mudança substancial na produção do conhecimento histórico. Eles pretenderam fazer uma Nouvelle Histoire, que representaria uma ruptura com o que denominavam história tradicional, história historizante ou história positivista (REIS, 1994). Bloch e Febvre fundaram a revista dos Annales, que teve quatro títulos: Annales d' histoire économique et sociale (1929 - 39); Annales d' histoire sociale (1939 - 1942,45); Mélanges d' histoire sociale (1942 - 4); Annales : économies, societés, civilisations (1946) (BURKE, 1997).
} 
À época, a propagação da necessidade da escola se fez em ampla ênfase dada à continuidade da formação de uma sociedade brasileira civilizada. No entanto, houve uma expressiva distância entre os discursos e a concretização da escolarização (VEIGA, 2007). Refletimos conjuntamente com a figura do inspetor sobre como se deu o processo de construção da escolarização no Brasil. Ainda durante a pesquisa observamos que, com a finalidade de atender aos propósitos da ideia de nação brasileira, iniciam-se as reformas educacionais que divulgavam o acesso à educação primária, a exemplo da Constituição de 1824, que aponta a gratuidade dessa etapa da escolarização.

A Constituição outorgada de 1824 , fortemente centralizadora, em matéria de educação limitava-se a dois parágrafos do artigo 179: 'A inviolabilidade dos direitos civis e políticos dos cidadãos brasileiros, que têm por base a liberdade, a segurança individual e a propriedade, é garantida pela Constituição do Império pela maneira seguinte:

\$3 - A instrução primária é gratuita a todos os cidadãos;

$\$ 33$ - Colégios e universidades, onde serão ensinados os elementos das ciências, belas letras e artes'. (SUCUPIRA, 2001, p. 57)

A Constituição Imperial traz em seu texto a instrução primária como direito de todos. No entanto, havia uma grande distância entre o real e o legal, como nos confirma Carvalho (1981, p. 51): “[...] a elite era uma ilha de letrados num mar de analfabetos”. Pelos relatórios de presidentes das províncias, dos diretores gerais de Instrução Pública e inspetores, que serão analisados durante o desenvolvimento do texto, poderemos delinear as dificuldades dessas instituições para enfrentarem problemas de formação dos professores, de questão salarial, de espaço físico e de material didático. As normas sociais estabelecidas eram definidas pela elite política bacharelesca, com o olhar a partir do lugar de formação, na Universidade de Coimbra. Dessa forma, esses eram os primeiros responsáveis pela constituição do aparato legal da nova nação.

Segundo Castanha (2006), certamente o poder estatal viu-se fortalecido pelo crescimento da instrução superior, uma vez que esta preparou os quadros administrativos com o propósito de homogeneidade envolvendo toda a camada privilegiada socialmente. Por fim, faz-se necessário compreender quem eram esses inspetores e de qual lugar social falavam. Em contato com os diversos documentos sobre 
a educação alagoana oitocentista durante o desenvolvimento desta pesquisa, optamos por conservar nas citações ora apresentadas a escrita da época, preservando, assim, a riqueza do idioma português de então.

\section{A Inspeção Escolar no Império}

Desde as primeiras tentativas de implantação da instrução pública no Brasil, por volta de 1830, quando Alagoas também anunciava seus primeiros passos, coube ao professor a responsabilidade por todas as atividades desenvolvidas na escola. Assim estava posto nas Instruções Provisórias para Regimento das Aulas de Ensino Primário da Província das Alagoas em 1859:

Art. $4^{\circ}$. Os professores se portarão na aula com a divida circumspecção e decencia em seu vistuario: trasendo a casa sempre limpa e com o divido aceio, e fornecida d' agoa para os alumnos; e mostrarão sempre em seus actos a prudencia que requer o magisterio, para o que empregarão continuamente a persuasão e severas admoestações antes de usar de outros meios correctivos [...] (Instrução Pública, Ofícios Recebidos de $1854-1860$, M13 E 05)

O professor transformava seu ambiente familiar num espaço público, ou melhor, precariamente público. Assim, comentava o primeiro tenente de artilharia, engenheiro José Antônio Marques: “As escolas públicas, em Maceió, não possuem instalações especiais apropriadas aos fins a que se destinam, funcionando em casas particulares, no próprio domicilio dos professores, onde a população escolar vive em perfeita prisão, sem ar, sem luz" (apud VERÇOSA, 2001a, p. 50).

Até meados do século XIX, cabia aos inspetores paroquiais, em nome da província, a responsabilidade pela substituição dos utensílios deteriorados, como também contratar com os proprietários casas para servirem de local para aulas do ensino primário. Conforme o ofício que segue:

Maceió Directoria Geral da Instrucção Publica - 11 de julho de 1859 №. 177 $1 \mathrm{llm}{ }^{\circ} \mathrm{Exm}^{\circ}$ Senhor 
Pela copia inclusa verá V. Exa . que se acha celebrado pelo Inspector Parochial respectivo o contracto de aluguel com a proprietaria da caza em que existe a eschola publica de $1^{\text {as }}$ lettras da povoação do Carurusinho, municipio da Imperatriz, pela quantia mensal de quatro mil reis, e pelo praso de seis annos a contar de 15 de outubro de 1854 , desde quando está adita caza ocupada pela mesma escola e porque me parece nos termos de [...] a approvação de $V$. Ex ${ }^{a}$., espero que se dignará de mandar expedir suas ordens á Repartição competente para o pagamento dos alugueis na forma do contracto, se for este approvado por V. Exa., ou não mandar de outro modo.

Deos Guarde a V. Ex .

ElI $^{\mathrm{m}^{\circ}} \mathrm{Ex}^{\mathrm{m}^{\circ}}$ Senhor Doutor Agostinho Luiz da GamaPresidente da Provincia

O Director da Instrucção Publica - José Corrêa da Silva Titara. (Instrução Pública, Ofícios Recebidos de 1854 -1860, M13 E05)

A partir de 1868, os referidos contratos ficaram sob o encargo dos professores. Para tal fim recebiam uma gratificação que foi fixada em lei:

\author{
ANNO de 1867 \\ ACTOS ADMINISTRATIVOS \\ III \\ DECISÕES, ORDENS E ACTOS DA PRESIDENCIA \\ DELIBER. DA PRESID. \\ DE $1^{\circ}$ DE MARÇO DE 1867
}

Regula alugueis das casas de aulas publica

$\mathrm{N}^{\circ} 258$ - O presidente da provincia manda que d'ora em diante se observe a tabella desta data, regulando os alugueis das casas em que funccionam as escolas publicas da provincia, cuja importancia deverá mensalmente ser entregue aos respectivos professores como parte de seus vencimentos, os quaes ficarão assim obrigados a ter casas nas condições de servirem para semelhante fim.

Ficam de nenhum effeito os contractos de locação de predios, ainda existentes (*) - José Martins Pereira de Alencastre.

(*) A tabella que acompanha a esta deliberação tem soffrido algumas modificações, sendo ultimamente substituida por outra (em 1871) baixada por officio da presidencia sob. n. 36 de 08 de Fevereiro desse anno. (GALVÃO; ARAÚJO, 1870, p. 405)

Dessa forma, se por um lado, o professor, como responsável pelo pagamento dos aluguéis das escolas, tornava essa ação menos burocrática, por outro lado, havia alguns impasses, como o apresentado pelo diretor geral da Instrução Pública, sobre a condição física da escola e a dificuldade encontrada pelo professor de alugar uma casa apenas com 
a finalidade de ministrar aulas, visto que a gratificação recebida era insuficiente. De modo que o espaço onde iriam ser desenvolvidas as aulas não tinha condições físicas para a referida atividade.

As exigências estavam postas, a conduta do (a) professor (a) era um requisito fundamental para sua aprovação. A vida do (a) candidato (a) seria observada para verificar sua moralidade. Não havia preocupação em melhorar o nível de conhecimento dos docentes, visto que a criação da primeira escola normal para a formação de professores no Brasil deu-se em 1835, na cidade de Niterói.

Em Alagoas, "Somente em 1836 é que vai ser regulamentado o funcionamento das escolas de primeiras letras, transcorridos quase vinte anos de autonomia políticoadministrativa da região" (VERÇOSA, 2001a, p. 163).

A situação física das escolas se constituía em um problema para o desenvolvimento da instrução pública, e como se não bastasse, o professor de instrução primária era moralmente ofendido em todos os âmbitos, e havia um discurso que apontava para a sua incapacidade em relação ao cargo. Esse enquadramento moral era parte de uma mentalidade conservadora. Assim eram caracterizados os professores: "[...] 'a confundir-se com os meios de vida ordinários, simples ganha-pão de umas tantas mediocridades, que a exploram com a sofrequidão de quem não tendo aptidão para mais nada, dela se socorrem como o mais fácil e ultimo recurso"' (COSTA, 1931, p. 23).

Ser professor de primeiras letras chegou a ser visto como uma atividade de pouco valor intelectual, moral e financeiro. A fragmentação dos níveis de ensino, divididos em instrução primária ${ }^{2}$, secundária e superior, reforçou uma hierarquia presente ainda em pleno século XXI. Por meio dessa “organização”, os professores foram colocados em lugares diferentes hierarquicamente. O valor da remuneração acompanhou essa localização; “Um mestre de primeiras letras recebia anualmente entre 80\$000 e 150\$000, enquanto um professor de filosofia podia ganhar até 460\$000" (VEIGA, 2007, p. 137).

Os professores de primeiras letras, no início e meio do ano, deveriam fazer a matrícula dos alunos e enviá-la ao governo pelos inspetores, a fim de que o governante

\footnotetext{
${ }^{2}[. .$.$] escolas primárias de primeiro grau, isto é, aquelas que o regulamento de 1854$ chama de escolas de instrução elementar (ALMEIDA, 2000, p. 102).
} 
tomasse conhecimento do número de alunos para, então, pagar o ordenado do professor. Assim,

Na capital e vilas de Maceió e Penedo [1836] a matricula não poderá ser menor de 50 alunos; nas demais vilas, de 20: nas povoações, de 12. Nenhum professor poderá cobrar o ordenado sem que apresente atestado de que a escola é freqüentada por aqueles numeros de alunos e que estes tem algum aproveitamento. Os professores além dos atestados das camaras municipais e dos parocos, os quais ficam por esta lei obrigados a fiscalizar o fiel cumprimento dela, a vista da matricula ou mapas que lhes deverão ser apresentados e do resultado da fiscalização darão atestado debaixo de juramento de seus cargos. (MOACYR, 1939, p. 565)

Como vimos, para receberem seus ordenados os professores tinham que comprovar o número de alunos, sobretudo a quantidade dos que frequentavam a escola. Outro aspecto importante era a apresentação da aprovação da Câmara e do pároco. Constava na Lei $\mathrm{n}^{\circ}$. 21, de 9 de março de 1836, que os professores “além dos attestados das camaras, ficam igualmente obrigados a apresentar attestados dos parochos respectivos [...]", uma tentativa de controle sobre os professores, sendo esses religiosos ou leigos; a política do apadrinhamento era responsável não só pela indicação desses, mas até pelas condições de receberem seus ordenados.

O regulamento de 20 de outubro de 1836 estabelece que a inspeção das escolas primárias será exercida por pessoas nomeadas pelo presidente da província. Devido ao fato de o Decreto de 1834 atribuir às províncias a responsabilidade pela educação elementar e secundária, cabia a essas legislar sobre esses níveis de educação. Eis uma das razões que explica o grande número de leis nas províncias brasileiras durante o Império. Embora, conforme documentação da época, a legislação em quase nada contribuiu para a melhoria da educação:

Estado actual Pessoal

O pessoal do professorado é o mesmo com mui pequena modificação, e os professores vão servindo sem a precisa aprendisagem que os habilite ao ensino, justiça porém seja feita, alguns ha que pelo seu zelo, dedicação, moralidade e capacidade intellectual se tem tornado dignos de verdadeiros encomios [...] (ESPÍNDOLA, 1866, p. 3) 
Com todas essas dificuldades, pouca atração era vista na carreira do professor, ao ponto de poucos quererem exercer essa profissão. Costa (1931, p. 38) afirma que: “O magistério, porém, não seduzia. As aspirações dos moços, principalmente dos abastados, voltavam-se de preferência para os cursos jurídicos". Essa preferência ocorria porque o grau de bacharel apresentava-se como um curso de cultura geral, dando ao seu portador o acesso aos cargos públicos e o exercício da função política (VERÇOSA, 2001b).

A elevação de Alagoas à condição de Comarca começa a despertar o interesse pelo bacharelado entre os filhos de senhores de engenho, assegurando para esses outras condições de prestígio e novos cargos públicos, como "[...] Corregedor, Comandante Militar, Juízes Ordinários, Camaristas, Capitães-Mores, etc." (VERÇOSA, 2001b, p. 53).

É importante dizer que esse interesse pelo bacharelado se aprofundou durante a fase provinciana de Alagoas, pois, como havia uma carência de pessoas intelectualmente aptas a ocuparem cargos na administração pública e política e, já estando em pleno funcionamento a Faculdade de Direito de Recife, coube aos senhores de engenho enviar seus filhos para posteriormente assumirem os postos de comando que aumentavam em número, em razão da autonomia política com a criação da Província.

As exigências continuavam para o magistério. A Lei $n^{\circ} .524$ de 3 de maio de 1870 determina: "Só podem exercer o magisterio da instrucção publica primaria os cidadãos brazileiros que provarem idade maior de vinte e um annos, moralidade e capacidade profissional, guardadas as disposições vigentes e o regulamento da escola normal”.

Tais constatações nos apontam que havia uma preocupação em contratar professores que já tivessem experiência, como também um determinado número de alunos matriculados.

O artigo 15 do Regulamento de Instrução Primaria (I) da Província de Alagoas registra que

O parecer dos examinadores ácerca da idoneidade profissional dos candidatos será enviado por intermedio do director geral ao presidente da provincia, para prover o candidato que mais se houver distinguido no exame, devendo em iguaes circumstancias ter preferencia os que forem casados e aquelles que já houverem prestado serviço no exercicio de algum emprego publico. (p. 247) 
Em seguida, a ocorrência descrita pelo Senhor José Correia da Silva Titara, Diretor da Instrução Pública, vem nos apontar, conforme versão publicada no periódico “o tempo", como era a relação entre o diretor e os professores:

№. 312 Maceió Dir ${ }^{a}$ Geral da Instrucção Publica 3 de setembro de $1857=$ $\mathrm{III}^{\mathrm{m}}$ Senhor $=$ Publicando o Periodico $=$ Tempo $=$ em o n. 431 distribuido hontem aqui, que eu na visita que fiz ultimamente nessa Cidade desacatára a uma das Professôras dirigindo-lhe [...] na presença de suas alumnas, usando dos seguintes termos = estas innocentes são umas malcreadas, não sei de que serve terem ellas uma Professôra que não Ihes dá creação, e outras que taes bellezas =; e aposto que não seja para admirar, sendo porem para notar que as conhecidas redactoras de tal periodico se lembrassem de inventar semelhante facto sabendo talvez que eu me desgostei do estado em que achei uma das aulas do sexo feminino dessa Cidade, e que alguma noticia de lá viesse, convem que V.S. se dirija officialmente a cada uma das duas Professôras e exija que Ihe respondão se é verdade que eu proferisse aquelas palavras ou outras quaesquer na aula tendentes a censura - las ou reprehende-las em presença de suas alumnas, devendo ellas accrescentar qualquer circunstancia de que tenhão noticia, que podesse dar lugar a publicação de semelhante facto.

V.S. comprehende bem a necessidade de exigir taes informações com urgencia, e peço-lhe que me remetta os originaes com a devida segurança.

Deos Guarde a V. S. - $I \mathrm{II}^{\mathrm{m}^{\circ}}$ [...] Senhor Candido José Alves da Silva, Inspector Parochial das aulas da Cidade da Alagôas - O Director da Instrucção Publica, José Corrêa da Silva Titara. (Instrução Pública, Ofícios Recebidos de 1857-1858, M12 E05)

O documento demonstra como a escola se tornara um espaço de moldamento conforme as exigências postas pela autoridade escolar, no caso o Diretor da Instrução Pública, que reduz à inutilidade a função da professora, afirmando que se essa não "servir para dar criação às alunas não serve para mais nada". Nessa perspectiva, o ofício do professor não está relacionado ao ato de ensinar, e sim a alguém que está responsável por regrar comportamentos.

O respeito à hierarquia não permitia ao docente se contrapor às determinações da autoridade escolar. A tentativa de moldagem não era apenas em relação ao aluno, mas iniciava-se no controle das ações dos professores, que iriam servir de exemplo para seus alunos. No entanto, o documento aponta que o diretor trata de justificar seus atos, 
demonstrando assim que também havia censura em relação às atividades desenvolvidas por este.

Contrapondo-se a essa visão, as professoras acusam o diretor pelos desacatos verbais sofridos na presença de suas alunas. Tais acusações vêm nos mostrar que, apesar do diretor ter a função de ser o elo entre a instância governamental (Presidente da Província) e os inspetores escolares, os professores não aceitavam passivamente as avaliações, censuras e acusações feitas por ele. Concluímos, portanto, que as ações de vigilância realizadas pelos inspetores e/ou diretores sofriam a resistência dos professores, caracterizando a escola como um espaço de conflito.

\section{Inspeção Escolar e a regularização do sistema de ensino}

Durante o século XIX houve uma disseminação de leis, regulamentos e decretos relacionados à educação; estes eram fundamentados nos países considerados civilizados. O objetivo era a constituição de um sistema educacional pautado na hierarquia estabelecida socialmente.

Regra geral, o valor atribuído às letras era pouco nas escolas, o foco principal não era a aprendizagem, e sim o regramento, desde que ele veiculasse um modelo moral, nos moldes impostos pela elite política. Espíndola (1866) reclama a falta de um lugar que habilite o magistério, embora reconheça aqueles docentes que por dedicação, moralidade e capacidade intelectual se tornem dignos de elogios. Assim, competia aos inspetores o controle das ações docentes. Porém, como já vimos relatando, a educação “assumida" pelo Estado não ofereceu condições para que os professores aplicassem uma metodologia adotada por este.

Com "A chegada de D. João VI existiam em todo território alagoano uma cadeira da língua latina e uma escola de primeiras letras na sede da comarca e uma escola primaria na vila de Santa Luzia do Norte, subvencionadas pelo governo" (COSTA, 1931, p. 5). Dessa forma, a vigilância e as cobranças em relação ao professor estavam descritas em diversos documentos, como, por exemplo: 
REGULAMENTO DE 21 DE OUTUBRO DE 1836 PARA AS ESCHOLAS DE PRIMEIRAS LETTRAS DA PROVINCIA DAS ALAGÔAS

Rodrigo de Souza da Silva Pontes, presidente da provincia das Alagôas, em cumprimento do artigo 13 da Lei Provincial de 9 de Março do corrente anno ordena que se observem como Regulamento das escholas de $1^{\mathrm{a}} \mathrm{s}$ lettras desta provincia as seguintes determinações. Artigo $10^{\circ} \mathrm{A}$ inspecção das escholas de instrucção primaria que se concede ao governo da provincia no art. $1^{\circ}$ da lei provincial de 9 de Março do corrente anno, será exercida por meio de pessoas nomeadas pelo mesmo governo. Art. 2..$^{\circ}$ As pessoas assim nomeadas terão a seu cargo a inspecção das escholas de um, de dous, ou mais municipios, conforme se julgar conveniente. Art. $3 .^{\circ}$ Todos os professores de cadeiras de instrucção primaria serão obrigados a prestar todas e quaesquer informações, que lhes forem pedidas pelos encarregados da inspecção, logo que estes lhes apresentem o officio de sua respectiva nomeação. Art. $4 .^{\circ}$ Os encarregados da inspecção exercerão sempre as funcções designadas no art. $1^{\circ}$ da lei provincial de 9 de Março deste anno e as designadas no art. $6 .^{\circ}$ da mesma lei, quando assim lhes for positivamente ordenado. Art. $5 .^{\circ}$ Os encarregados da inspecção das ditas escholas deverão apresentar a este governo em cada um semestre uma informação circumstanciada do estado dellas, para o que visitarão as escholas respectivas, exigindo dos professores os esclarecimentos necessarios. Art. $6^{\circ}$ Os professores terão um livro de matricula rubricado pelos presidentes das camaras, onde se declarem os nomes dos discipulos e de seus paes, a patria, idade, dia, mez e anno de entrada e sahida, comportamento, applicação e adiantamento de cada um dos discipulos, d'onde extrahirão uma exacta relação, que deve ser apresentada a este governo nos tempos marcados no art. $2 .^{\circ}$ da citada lei de 9 de março. Art. $7^{\circ}$ Este governo subministrará pelas rendas da provincia a cada um dos professores o livro de que trata o artigo antecedente. Art. $8^{\circ}$ Sendo os mestres na educação moral verdadeiros paes de seus discipulos, devem ter todo cuidado de os ir formando de genio docil, inspirando-lhe temor a Deus, gôsto á sciencia, amor á verdade, obediencia á lei e respeito aos superiores. (GALVÃO; ARAÚJO, 1870, p. 181-182)

O serviço de inspeção requeria das instituições escolares uma homogeneização na condução do trabalho escolar. Para isso, vários instrumentos foram utilizados: os relatórios, os ofícios e os mapas escolares. Estes eram entregues pelos professores, de forma sequencial, aos inspetores paroquiais, inspetores gerais de estudos e/ou ao diretor da instrução pública, que condensavam as informações, a fim de enviarem ao presidente da província.

Esses mapas ofereciam a possibilidade de se fazer um acompanhamento quantitativo e qualitativo das escolas, o acesso a uma série de informações, a exemplo do 
número de alunos, nomes, filiação, naturalidade, conduta, cor da pele, diversidade (SILVA, 2009).

O decreto $n^{\circ} .1331$ A de 17 de fevereiro de 1854, expedido pelo governo da Corte, no seu art. $66, \S 5^{\circ}$, dispunha que os professores públicos teriam a "obrigação" de remeter os seguintes mapas: “[...] no fim de cada trimestre, hum mappa nominal dos alumnos matriculados, com declaração de sua frequencia e aproveitamento; e no fim do anno um mappa geral, comprehendendo o resultado dos exames, e notando d'ntre os alumnos os que se fizerão recommendaveis por seu talento, applicação e moralidade".

Na Província das Alagoas, conforme o Regulamento de Instrução Primária, era atribuição do diretor geral: "Apresentar ao presidente da provincia todos os annos até o fim de Janeiro impreterivelmente um relatorio sobre a instrucção publica da provincia, indicando as reformas ou medidas que julgar convenientes, e ajuntando mappas do numero das escolas, professores e dos discipulos de cada uma dellas" (GALVÃO; ARAÚJO, 1870, p. 244).

A referida legislação, no Art. $5^{\circ}$, determina que em cada município seja criado um conselho de inspeção, composto de um inspetor, que o presidirá, e mais dois membros. Uma das atribuições desse conselho é "Transmittir ao director mappas semestraes organisados em face dos que lhe serão remettidos pelos inspectores parochiaes".

Nos mapas dos Estudantes anuais constam: número do aluno, nome, filiação, idade, naturalidade, entrada, qualidade, habilidade, aplicação, adiantamento; já nos mapas de alunos mensais constam: número do aluno, nome, filiação, idade, naturalidade, adiantamento, habilidade. Os mapas trimestrais ou mapas de frequência foram uma "[...] estratégia de comprovação de efetivo exercício docente (documento necessário para o recebimento do salário) e de viabilidade da escola (atestado imprescindível de atendimento ao número mínimo de alunos exigido por lei para manutenção da aula) [...]” (VIDAL, 2008, p. 43-44). O mapa anual trazia informações mais gerais sobre o grau de aprendizagem do aluno.

Esses mapas se apresentam como fontes de registro, estão carregados de dados que, devido às cobranças por parte do governo, fazem-nos desconfiar da sua autenticidade. Entre as cobranças estão: “As escolas frequentadas somente por 15 
alumnos serão supprimidas, quando isto não dependa do professor" (Art. 17 da Resolução $\left.n^{\circ} 424,1864\right)$. Assim, para não ter sua escola fechada, é possível que os professores alterassem dados, o que pode ser caracterizado como um modo de se opor a uma das exigências relativas ao funcionamento de uma escola.

Veiga (2007, p. 185) informa que "A documentação oficial e as críticas presentes na imprensa da época levam à constatação de que a qualidade tanto dos estudos secundários quanto dos estudos superiores era sofrível, com raras exceções”. Em relação à quantidade de aulas Verçosa (2001a, p. 33-34) nos fala que: "Em 1835 contavam-se na Província 5 aulas de latim, 2 de francês, 1 de retórica, 1 de filosofia e 1 de aritmética. Dez cadeiras de ensino secundário destinadas aos rapazes ricos, frequentadas por cento e poucos alunos".

\section{Considerações finais}

O inspetor tinha papel fundamental no controle da entrega dos mapas. Este era o elo entre o professor e a instância governamental, na pessoa do Diretor de Instrução Pública. Por meio dos mapas, o inspetor fiscalizava o efetivo trabalho do professor, as frequências dos alunos, importantes dados para a manutenção, continuidade ou fechamento das escolas em determinadas regiões.

Possivelmente por meio de relatórios dos inspetores, formulavam-se conceitos sobre o trabalho docente da época. O trabalho dos inspetores, apesar de ser desenvolvido de forma burocrática, apresentava aspectos de cunho intelectual; diagnosticavam os problemas educativos e informavam as condições e necessidades das escolas. Também cabia aos inspetores propor mudanças no âmbito pedagógico, uniformizar as práticas pedagógicas e administrativas; diagnosticar e propor mudanças para os problemas físicos da escola e a situação salarial dos professores; disciplinar e modelar a ação dos professores e alunos. O que demonstra um papel analítico e propositivo, realizado no cumprimento de suas funções, cabendo à instância superior a decisão final.

Os desdobramentos dessas informações possivelmente ajudavam a constituir as políticas educacionais da época. Além do controle pelo que ocorria no interior da escola, 
o inspetor era responsável por aluguéis de casa-escola, solicitação de salário para os professores, solicitação de licença-médica, material escolar.

Aos inspetores cabia também a tarefa de verificar quais as localidades que precisavam de cadeiras de instrução elementar e as que deveriam ser fechadas, a depender do número de alunos. É possível que isso reforce a ideia de que essas informações foram fundamentais para a elaboração do sistema de ensino.

Na Revista de Ensino de Alagoas (1927), no artigo "O ensino primário no Estado", o autor expressa as dificuldades da confiabilidade na estatística elaborada até então: “É um facto que as estatisticas escolares em Alagôas nunca deram uma idéa, sequer approximada, do estado da população infantil, quanto á alfabetização”. Continuando, remete à utilização dos mapas escolares, ainda que estes não sejam uma fonte fidedigna, como qualquer outro documento.

A fonte donde ellas provinham - o professorado- não era isenta de suspeição, porque os mappas escolares organisados mensalmente para o effeito de recebimento de ordenados e que serviam de base á estatistica geral, eram sempre fantasticos. Os algarismos que elles registravam, sem fiscalisação de especie alguma, cresciam ao sabor das conviniencias dos professores, empenhados em dar á Directoria Geral a illusão de que, no interior, o magisterio cumprea rigorosamente o seu dever. (REVISTA DE ENSINO, 1927, p. 43)

Uma outra observação a respeito do uso dos mapas em nossa pesquisa é que estes são documentos que se transformam em fonte histórica, na medida em que os interrogamos, indagamos o lugar social de quem o escreveu, com qual propósito, e procedemos a um cruzamento de informações com outras fontes que tratam do assunto. Assim nos lembra Pesavento:

Sem dúvida, o historiador se apoia em textos e imagens que ele constrói como fontes, como traços portadores de significado para resolver os problemas que se coloca para resolver. Mas é preciso ir de um texto a outro texto, sair da fonte para mergulhar no referencial de contingência no qual se insere o objeto do historiador. (PESAVENTO, 2005, p. 65) 
Somente assim alargamos o conhecimento sobre o tema, tornando o documento mais generoso. Vale ressaltar que grande parte da literatura que nós temos de história da educação brasileira, especialmente do Império, foi profundamente pautada nos dados gerados pelos inspetores escolares, que realizavam o trabalho mais de perto com os professores, traziam o número de alunos, informavam a situação das escolas e o uso de material didático, assim como a ausência destes em sala. A situação administrativa e pedagógica da escola era passada pelo filtro do inspetor. Assim, ainda que os mapas não fossem uma fonte segura de informação, eram utilizados para as diversas ações que dependiam de dados educacionais, o que os transforma em um instrumento fundamental à época, sobretudo para pesquisadores que trabalham com fontes oficiais.

Vários eram os motivos pelos quais os professores, em diversas situações, realizavam suas atividades com dificuldades. O poder público pouco investiu na melhoria do conhecimento dos professores, apesar de toda uma exigência por parte da legislação. As dificuldades dos docentes em desenvolverem suas atividades não decorriam apenas da questão salarial. Iam mais além: não havia um lugar de formação profissional, nem espaço adequado para o professor desenvolver suas atividades, sendo utilizados espaços os mais estranhos aos seus afazeres escolares, como a sua própria casa. Enquanto os discursos se reportavam ao método e à legislação, como antídoto para resolver todos os problemas, omitia-se que as leis se tornavam imposições, na medida em que no contexto econômico e de valor atribuído à educação, não havia condições de atender ao que estava determinado.

Como a educação é um processo que transita em outras instâncias (social, política e econômica), na escola vão se reproduzindo costumes, valores e crenças dos que detinham o poder, representado por sujeitos diferentes em espaços diferenciados. Daí a vigilância no trabalho do professor tornar-se cada vez mais importante. Pois se fazia necessário reproduzir na escola o discurso do governo. Assim nos lembra o historiador alagoano:

A política que partia dos centros rurais, os engenhos de açúcar, era baseada no prestígio que os senhores davam à coroa: primeiro, à coroa lusa, e contentavam-se com o controle das câmaras municipais, dos postos representativos; depois, à coroa brasileira quando recebiam 
representações mais altas - as deputações provinciais ou gerais, a senatoria do Império, as comendas, os títulos de grandeza; e mantinhamse como esteio da situação política nacional. Mesmo as lutas partidárias entre os conservadores e liberais, não perturbaram o ritmo dessa orientação: de pleno apoio à coroa, de segurança das instituições monárquicas. (DIÉGUES JÚNIOR, 1980, p. 194)

Ocupar cargo público foi uma das estratégias mais viáveis utilizadas pela elite para se perpetuar no poder político, econômico, social e cultural, e assim dar continuidade aos propósitos do governo, por entender que qualquer que fosse o cargo público, seria “[...] uma comissão do Rei, sua investidura transformava quem o detinha em portador de autoridade, conferindo-lhe, ao mesmo tempo, por um fenômeno de interpenetração inversa de valores, a marca da nobreza" (VERÇOSA, 2001b p. 28). Esse servidor público revestia-se de autoridade e a utilizava para defender os interesses de quem o beneficiou. Em relação a Alagoas, Moacyr (1939) escreve:

1836 - A inspeção das escolas primarias será exercida por meio de pessoas nomeadas pelo presidente da província. Estas pessoas terão a seu cargo um ou mais municípios conforme se julgar conveniente. Todos os professores são obrigados a prestar informações aos inspetores; e estes ao governo em cada semestre. - "Sendo o mestre na educação moral verdadeiro pai de seus discipulos deve ter todo o cuidado de os ir formando de genio docil, inspirando-lhes o temor a Deus, gosto ás ciencias, amor á verdade, obediencia á lei e respeito aos superiores. São obrigados por isso a evitar, quando possivel, a nimia severidade e os castigos fisicos, conduzindo os discipulos pelo estimulo ao pudor, liberdade e emulação". (MOACYR, 1939, p. 566)

Retornando à discussão anterior, a citação expõe uma fiscalização mais cuidadosa nas escolas de primeiras letras, e isso é explicável se considerarmos que as crianças precisavam se apropriar de conceitos e hábitos comportamentais; assim, cabia ao professor estabelecer o que os alunos deveriam aprender.

O que seria ensinado nessas escolas precisava estar sob vigilância, acompanhado com o discurso da universalidade da instrução. Conforme Moacyr (1939), em abril de 1843, a Assembleia Legislativa decreta que haverá na capital um Conselho permanente de instrução pública, formado por membros nomeados pelo presidente da província, 
competindo a este conselho fiscalizar as aulas da província, por si ou comissões, sem que, contudo, fique prejudicada a fiscalização do governo.

Em relação às cidades e às vilas, caberá ao referido conselho nomear uma comissão para fazer a inspeção das escolas, conduta dos professores e número de alunos. Cabe ao conselho demitir os membros da comissão que esse considerar omissos e nomear outros.

O Diretor da Instrução Pública tinha como atribuição elaborar relatórios indicando as reformas ou medidas que julgasse convenientes, os quais eram encaminhados ao presidente da província. Cabia ao Diretor Geral da Instrução Pública propor a substituição de cargos, conforme podemos constatar na citação que segue:

\section{GOVERNO DA PROVINCIA}

Expediente do dia 14 de novembro de 1859

Portaria - O presidente da provincia, sobre proposta do director geral da instrucção publica por officio n. 389 desta data exonera o vigario da freguezia do Poxim, Antonio Eustaquio Alves da Silva, do cargo de inspector parochial da mesma freguezia e nomeia para substitui-lo ao cidadão Francisco Lopes dos Santos Lima, proposto pelo sobredito director. - Communicou-se ao referido director em resposta ao citado officio. (Diário das Alagoas, 28 de novembro de 1859, p. 1)

Quem realizava o serviço de inspetoria eram pessoas de confiança do governo, enquanto este se baseava nas propostas do diretor de instrução pública para escolher seus "representantes", constituindo assim uma hierarquia de poder.

\footnotetext{
Directoria Geral de Instrucção Publica Maceio, 18 de janeiro de 1861

Achando-se vago o logar de Inspector Municipal das aulas publicas e particulares de Pão de Assucar, proponho a V. Exa para exercer esse cargo o Dr. Promotor Publico da Camara que pertence esse termo, Anacleto de Jesus Maria Brandão Filho, esse concorre aos precisos requisitos para o bom desempenho do emprego.

Deos guarde a $\mathrm{V} \mathrm{EX}^{\mathrm{a}} \mathrm{Exm}^{\circ}$

Dr Pedro Leao Velloso

Presidente da Provincia

O Director da Instrucção Publica José Corrêa da Silva Titara. (Instrução

Pública, Ofícios Recebidos de 1861-1862, M14 E05)
} 
A lei $\mathrm{n}^{\circ} .21$, de 9 de março de 1836, determina que as cadeiras então existentes e as que se criarem ficam sujeitas à inspeção do presidente da província ou pessoa de sua confiança, que devem inspecionar se os professores cumprem seus deveres. No entanto, não encontramos quais os critérios para a escolha dessas pessoas que serão os "olhos" do presidente da província. A inspeção escolar, desde seu início, foi realizada por vários segmentos da sociedade, como podemos comprovar nas citações que seguem:

O ensino dado nas referidas aulas publicas continuará a ser gratuito: as horas do mesmo ensino serão determinadas pelo regulamento da instrucção publica e ordens em vigor, e a inspecção continuará a ser feita pelos membros do governo da instrucção publica, pelo presidente da camara municipal e inspector parochial respectivos (RESOLUÇÃO 450 de 17 de junho de 1865).

1870 - Uma lei de maio suprime os lugares de inspetor geral dos estudos e os inspetores paroquiais, e crea os cargos de diretor geral da instrução publica e de delegados literarios; o diretor é de livre nomeação do governo vencendo o ordenado de 1: 600 \$ e $800 \$$ de gratificação. No impedimento do diretor geral será nomeado um professor do Liceu. $\mathrm{Na}$ mesma lei se prescrevem as condições para apresentação do magisterio, as escolas que derem pouca frequencia devem ser regidas interinamente por pessoas idoneas. (MOACYR, 1939, p. 598).

A L. n. 524 de 3 de Maio de 1870 alterou a legislação anterior sobre instrucção publica. Restabeleceu o logar do director geral com os vencimentos de $2.400 \$$ ooors." (Regulamento de Instrucção Primaria. (1) da Província das Alagoas - Capitulo II - p. 243)

A fiscalização, como se depreende dos documentos citados, não se dava apenas no momento de examinar o conhecimento dos professores para assumirem o cargo de docente, continuava por meio da observação da vida dos professores e das visitas às escolas de onde se retiravam as informações para o controle das suas atividades. Os professores deveriam servir de exemplo para seus alunos, agir sempre demonstrando decência, moralidade e o credo no cristianismo. No Regulamento de 4 de setembro de 1870 - Província das Alagoas, em seu Artigo $1^{\circ}$, constava que: “O professor publico de instrucção primaria é obrigado: $\S 5^{\circ} \mathrm{A}$ convidar e levar a missa seus discipulos no $1^{\circ}$ domingo de cada mez, sempre que fôr possivel". A hierarquização era um ponto evidente na sala de aula, inclusive na delimitação das ações de cada um dos envolvidos: inspetor escolar, professor e aluno. O presidente da Província, Coronel Antônio Nunes de Aguiar, 
apresentava à Assembleia Legislativa a importância da criação de uma diretoria de instrução:

Relatorio Instrucção Publica - 1849

Senhores Deputados á Assembléa Provincial,

As grandes vantagens, que da creação deste estabelecimento tem de resultar para a instrucção publica, são por demais palpaveis, e por isso estou dispensando de ennumeral-as, tanto mais que vós ja vos tendes bem compenetrado dellas. Lembro entretanto a idéa de serem o seu Director e Secretario os encarregados de velar sobre a instrucção publica em geral da Provincia, ficando assim derogada a Lei de 6 de Abril de 1843, que creou o Concelho de instrucção publica. Julgo conveniente esta medida; porque a experiencia nos mostra, que os serviços gratuitos não produzem o effeito que se deseja, e nem é possivel esperar-se resultados proficuos, por isso mesmo que os empregados de tal Concelho, não percebendo subsidio, necessitão empregar-se em outros trabalhos donde tirem interesse, e aos quaes applicão todo o seu zelo e actividade. (BARROS, 2006, p. 436)

Ainda que o cargo de inspetor oferecesse prestígio político, havia a necessidade de regulamentar a profissão vinculando-a a um ordenado. Não é difícil encontrarmos críticas ao trabalho realizado pelos inspetores, entretanto, em busca de uma homogeneização e controle do ensino, o governo ampliava as atividades desenvolvidas por eles. A partir de 1853,

Ninguem poderá estabelecer escola particular, sob qualquer denominação, sem autorisação expressa do presidente da provincia; deverá o pretendente provar maioridade, bôa conduta civil e moral e idoneidade profissional. Esta prova será dada perante o inspetor municipal e mais dois examinadores. (MOACYR, 1939, p. 577)

Nessa perspectiva, tornava-se complicado realizar tais atividades sem remuneração. Vale ressaltar que nos poucos apontamentos sobre a inspeção na Província das Alagoas só encontramos registrada a remuneração para os diretores de instrução pública e inspetores gerais dos estudos. Dessa forma, alguns inspetores tinham que se afastar dessa função para assumirem outras atividades, como podemos comprovar no ofício que segue: 
Maceio 2 de julho de 1861

$\mathrm{N}^{\circ} 191$

IIIm $\mathrm{Ex}^{\circ}$ Senhor

O Inspector parochial da villa de Anadia Dr. [...] Eusebio de Assumpção por officio de 15 do mes proximo passado pede a V. Ex por meo intermedio sua exoneração do semelhante cargo, o que faz, diz elle, por que no desempenho das funcções do cargo de juiz municipal e de [...] da camara d' aquelle, não lhe resta o tempo preciso para a boa fiscalisação das aulas de sua jurisdição; V. Exa porem, por conveniencia da instrucção publica a vista da falta de pessôas outras tão idoneas para o cargo, não exonerará por certo.

Deos guarde a V. Ex ${ }^{\mathrm{a}}$

$\mathrm{Exm}^{\circ} \mathrm{Illm}^{\circ}$ Dr. Antonio Alves de Souza Carvalho

Presidente da Provincia

Ao Senhor Director

Manoel Lourenço (Instrução Pública, Ofícios recebidos de 1861-1862, M14 E05)

O Regulamento Orgânico da Instrução Pública recomendava que houvesse uma hierarquia entre os inspetores paroquiais, professores e inspetores gerais; cabia aos inspetores paroquiais a responsabilidade de intermediar a comunicação entre professor e inspetor geral. O referido regulamento trazia em seus artigos um tipo de administração com base numa hierarquia de poder de mando.

Art. 128 - Os Inspetores paroquiais serão nomeados pelo Presidente da Província, sobre proposta do Inspetor - Geral. Eles não poderão exercer o magistério público ou particular, e serão preferidos os que possuírem graus acadêmicos, ou que sejam de mais ilustração da localidade:

Art. 132 - Quando se tiver de dirigir ao inspetor da instrução usará de termos requisitórios e não imperativos.

Art. 133 - Todos os ofícios e requerimentos dirigidos por qualquer empregado da instrução pública ou particular ao governo, ou ao Inspetor - Geral, subirão por intermédio dos Inspetores paroquiais, que os transmitirão com informações. Excetuando-se as queixas contra os mesmos inspetores, as quais poderão subir diretamente à presença do Inspetor-Geral ou do governo. (Regulamento de 1873. In: SÁ; SIQUEIRA, 2000, p. 54 e 56)

Ainda em fevereiro de 1854, segundo o Decreto $1331 \mathrm{~A}$, foi estabelecido quem iria exercer a inspeção dos estabelecimentos públicos e particulares no município da Corte. 
Entretanto, na Província das Alagoas, já em 1853, a inspeção das escolas competia ao presidente da província, ao diretor geral da instrução pública, aos conselhos municipais e aos inspetores paroquiais.

\section{Referências}

ALMEIDA, Luiz Sávio de. Dois textos Alagoanos exemplares. In: ALMEIDA, Luiz Sávio de. Dois Textos Alagoanos Exemplares. Maceió: FUNESA, 2004, p. 8 - 18.

ALMEIDA, José Ricardo Pires de. Instrução pública no Brasil (1500 - 1889): História e Legislação. 2. ed. rev. São Paulo: EDUC, 2000.

ANDRADE, Antonio A. Banha de. A Reforma Pombalina dos estudos secundários no Brasil. São Paulo: Saraiva, 1978.

AZEVEDO, Fernando de. A Transmissão da Cultura. São Paulo: Melhoramentos, 1976.

AZEVEDO, Fernando de. A Cultura Brasileira: introdução ao estudo da cultura no Brasil. 3. ed. São Paulo: Melhoramentos, 1958.

BARROS, Francisco Reinaldo Amorim de. ABC das Alagoas: dicionário biobibliográfico, histórico e geográfico das Alagoas. Brasília: Senado Federal, 2005.

BARROS, Luiz Nogueira (org.). Falas, relatórios provinciais e mensagens governamentais de Alagoas de 1835 - 1930. Maceió: Imprensa oficial, 2006. 
BASTOS, Humberto. 0 desenvolvimento da Instrução Pública em Alagoas. Maceió: [s/e], 1939.

BASTOS, Maria Helena Camara. O Ensino Monitorial/Mútuo no Brasil (1827- 1854). In: STEPHANOU, Maria; BASTOS, M.H.C. (Orgs.). Histórias e memórias da educação no Brasil - século XIX. Petrópolis, RJ: Vozes, p. 34-51, 2005.

BLOCH, Marc Leopold Benjamin. Apologia da história, ou, $\mathbf{O}$ ofício do historiador. Rio de Janeiro: Jorge Zahar, 2001.

BORGES, Angélica. Ordem no ensino: a inspeção de professores primários na Capital do Império brasileiro (1854 - 1865), 2008. 287f. Dissertação (Mestrado em Educação) Universidade do Estado do Rio de Janeiro, Rio de Janeiro, 2008.

BORGES, Angélica. Ordem no ensino: a organização da inspeção de professores na Corte

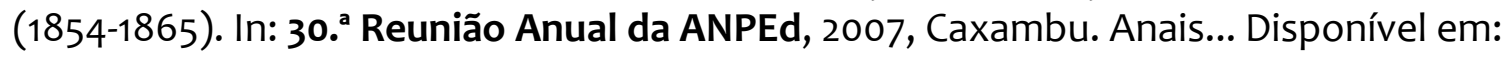
Acesso em: 13 mar. 2010.

BRANDÃO, Moreno. Os Presidentes das Alagoas. Maceió: [s.n.], 1975. BRASIL. Collecção das Leis do Império. Decreto 1331 A - de 17 de Fevereiro de 1854 - Regulamentos Para a Reforma do Ensino Primário e Secundário do Município da Corte, TOMO 17, Parte $2^{a}$, Secção $12^{\mathrm{a}}$, Rio de Janeiro, Typografia Nacional, 1854.

BRASIL. Lei de 6 de novembro de 1772. Disponível em:

<Www.ige.minedu.pt/upload//docs/Lei-6-11-1772.pdf - Similares>. Acesso em: 28 ago. 2009. BRASIL. Lei de 15 de outubro de 1827. Disponível em:

<www.pedagogiaemfoco.pro.br/hebo5a.htm>. Acesso em: 18 mar. 2010.

BURKE, Peter. A Escola dos Annales (1929 - 1989): a Revolução Francesa da historiografia. Trad. Nilo Odalia. São Paulo: Fundação Editora da UNESP, 1997.

CAETANO, Lucia Teixeira; LINS, Ana Maria Moura. Ensino secundário em Alagoas: Fundação e Expansão (1849-1930), 1997.

CARVALHO, Cícero Péricles de. Formação Histórica de Alagoas. 2. ed. Maceió. Grafitex, 1982.

CARVALHO, José Murilo de. A Construção da Ordem: a elite política imperial. Brasília: Campos, 1981.

CASTANHA, Andre Paulo. Escolas Normais no século XIX: um estudo comparativo. Revista HISTEDBR On-line, v. 32, p. 17-36, 2008.

CERTEAU, Michel de. A Escrita da História. 2. ed. Rio de Janeiro: Forense Universitária, 2008. 
COSTA, Craveiro. Instrução pública e instituições culturais de Alagoas. Maceió: Imprensa oficial, 1931.

CUNHA JUNIOR, Carlos Fernando Ferreira da. O Imperial Collégio de Pedro II e o ensino secundário da boa sociedade brasileira. Rio de Janeiro: Apicuri, 2008.

DIÉGUES JÚNIOR, Manuel. O Bangüê nas Alagoas: traços da influência do sistema econômico do engenho de açúcar na vida e na cultura regional. 2. ed. Maceió: EDUFAL, 1980.

DUARTE, Abelardo. História do Liceu Alagoano: desde sua criação até o ano de 1960. Maceió: [s.n], 1961.

ELIAS, Norbert. O processo civilizador. Rio de Janeiro: Jorge Zahar, 1994. ENCICLOPÉDIA BARSA UNIVERSAL. São Paulo: Editorial Planeta, 2007.

FERRARO, Alceu Ravanello. Analfabetismo no Brasil: desconceitos e políticas de exclusão. PERSPECTIVA, Florianópolis, v. 22, n. 01, p. 111-126, jan./jun. 2004.

FERREIRA, Aurélio Buarque de Holanda. Miniaurélio Século XXI Escolar: o minidicionário da língua portuguesa. Rio de Janeiro: Nova Fronteira, 2001.

GALVÃO, Olympio Euzébio de Arroxellas; ARAÚJO, Tiburcio Valeriano de. Compilação das Leis Provinciais das Alagoas de 1835 a 1870. Maceió: Typographia Commercial de Antonio Jose da Costa, 1870.

GALVÃO, Olympio Euzébio de Arroxellas; ARAÚJO, Tiburcio Valeriano de. Compilação das Leis Provinciais das Alagoas de 1835 a 1872. Maceió: Typographia Commercial de Antonio Jose da Costa, 1874.

GALVÃO, Olympio Euzébio de Arroxellas. Memória sobre os Conselhos Gerais da Província das Alagoas. 1829 a 1833. Revista do Instituto Arqueológico e Geográfico Alagoano, $n^{\circ} 14,4^{\circ}$ do volume $2^{\circ}$, p. $118,119$.

GONÇALVES, Rosemari Conti. Matrizes da ação inspetora no ensino catarinense: agentes

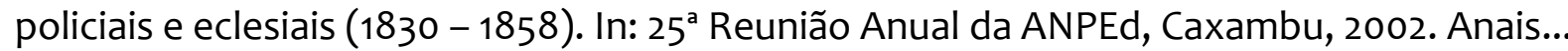
Caxambu, 2002. Disponível em: <http://

www.anped.org.br/reunioes/25/posteres/rosemarigoncalvesp02.rtf>. Acesso em: 20 mar. 2010.

GONDRA, José Gonçalves; SCHUELER, Alessandra. Educação, poder e sociedade no Império brasileiro. São Paulo: Cortez, 2008.

HOLANDA, Sérgio Buarque de. Raízes do Brasil. Rio de Janeiro: José Olympio, 1991. 132

LARA, Silvia Hunold. Os documentos textuais e as fontes do conhecimento histórico.

Anos 90. Porto Alegre, v. 15, n² 28, p.17-39, dez. 2008. 
LEVASSEUR, E. O Brasil. 2. ed. Rio de Janeiro: Bom Texto, 2001.

MADEIRA, Maria das Graças de Loiola. A pedagogia feminina das casas de caridade do Padre Ibiapina. Fortaleza: Edições UFC, 2008.

MADEIRA, Maria das Graças de Loiola. O Gabinete de Leitura e suas implicações na cultura escolar do Império - notas sobre a instituição no Nordeste brasileiro, In: XXIII Simpósio Nacional de História - História: Guerra e Paz, Londrina, 2005. Anais... Londrina, 2005.

MADEIRA, Maria das Graças de Loiola; SILVA, Rosilda Germano. Padres-mestres alagoanos: uma leitura de itinerários no Império. In: Il Congresso de História da Educação do Nordeste. Maranhão, 2007. Anais... Maranhão, 2007. MEMÓRIAS LEGISLATIVAS. Vultos do passado referências para a geração presente e futura. Maceió, 28 de dezembro de 1997.

MOACYR, Primitivo. A Instrução e As Províncias: subsídios para a história da Educação no Brasil 1834 - 1889 (Das Amazonas às Alagoas). vol.1. São Paulo/ Rio de Janeiro/ Recife/ Porto Alegre: Campanhia Editora Nacional, 1939.

NUNES, Antonietta d'Aguiar. A formação dos sistemas públicos de educação no sec. XIX e sua efetivação na província da Bahia. Revista do Instituto Geográphico e Histórico da Bahia, Salvador - Bahia, v. 99, p. 75-113, 2004.

NUNES, Antonietta d'Aguiar; MATOS, Maria Teresa Navarro de Britto; CABRAL, Ilma da Silva. Os Arquivos e a Memória da Educação na Bahia: Recordando localmente para conhecer globalmente. In: CASIMIRO, Ana Palmira Bittencourt S.; LOMBARDI, José Claudinei; MAGALHÃES, Lívia Diana Rocha (Orgs.). A Pesquisa e a Preservação de Arquivos e Fontes para a Educação, Cultura e Memória. Campinas, SP: Editora Alínea, 2009.

NUNES, Clarice; CARVALHO, Marta Maria Chagas de. Historiografia da educação e fontes. In: GONDRA, José Gonçalves (Org.). Pesquisa em história da educação no Brasil. Rio de Janeiro: DP \& A, 2005, p. 17 - 62.

PESAVENTO, Sandra Jatahy. História \& História Cultural. 2. ed. Belo Horizonte: Autêntica, 2005.

REIS, José Carlos. Nouvelle Histoire e tempo histórico: a contribuição de Febvre, Bloch e Braudel. São Paulo: Ática, 1994.

REVISTA DE ENSINO DE ALAGOAS, maio-junho de 1927, anno I, nº. 03, Maceió-Al, Orgão Oficial da Diretoria Geral da Instrução Pública de Alagoas. 
REVISTA DO INSTITUTO ARQUEOLÓGICO E GEOGRÁFICO ALAGOANO. In: A Instrução Pública nos Fins do Século XVIII. Officinas graphicas da Livraria MachadoJaraguá (Maceió), p. 139 - 140, 1931.

RIBEIRO, Maria Luisa Santos. História da Educação Brasileira: a organização escolar. $14^{\text {a }}$ ed. Campinas: Autores Associados, 1995.

SÁ, Nicanor Palhares; SIQUEIRA, Elizabeth Madureira (Orgs.). Leis e regulamentos da instrução pública do Império em Mato Grosso. Campinas (SP): Autores Associados/ SBHE, 2000.

SILVA, José Carlos de Araujo. Fontes Documentais para o Estudo do Cotidiano das Escolas pelo Método de Ensino Mútuo por meio da "Série Colonial" do Arquivo Público do Estado da Bahia. In: CASIMIRO, Ana Palmira Bittencourt S.; LOMBARDI, José Claudinei; MAGALHÃES, Lívia Diana Rocha (Orgs.). A Pesquisa e a Preservação de Arquivos e Fontes para a Educação, Cultura e Memória. Campinas, SP: Editora Alínea, p. 159 -174, 2009.

SIQUEIRA, Elizabeth Madureira. Luzes e Sombras: modernidade e educação pública em Mato Grosso 1870-1889. Cuiabá: INEP/ COMPED/EDUFMT, 2000.

SIQUEIRA, Elizabeth Madureira. Educação e Modernidade: uma dimensão plural modernas noções de tempo e espaço nas escolas públicas de Mato Grosso. Revista Educação Pública, Cuiabá, v. 8, n. 13, p. 122-142, 1999.

SUCUPIRA, Newton. O Ato Adicional de 1834 e a Descentralização da Educação. In: FÁVERO, Osmar (Org.). A Educação nas Constituintes Brasileiras 1823-1988. 2 ed. rev. ampl. Autores Associados, 2001. Col. Memória da Educação. Campinas (S.P). p. 55-67. VEIGA, Cynthia Greive. História da Educação. São Paulo: Ática, 2007.

VEIGA, Cynthia Greive. Escola pública para os negros e os pobres no Brasil: uma invenção imperial. In: Revista Brasileira de Educação, Campinas: Autores Associados, v. 13, n. 39, p. 502-516, set./dez. 2008.

VEIGA, Cynthia Greive; VIANA, Fabiana da Silva; MACHADO, Cláudia Maria José Peixoto. Delegados Literários da Instrução Pública: A construção de um novo ator social a partir da lei $n^{\circ} 13$ de 1835. In: V Congresso de Ciências Humanas, Letras e Artes, 2001, Ouro Preto. Anais... Disponível em: <http:// www.ichs.ufop.br/conifes/anais/EDU/edu1705.htm>. Acesso em: 23 mar. 2010. 134 .

VELLASCO, Ivan de Andrade. Clientelismo, ordem privada e Estado no Brasil oitocentista: notas para um debate. In: CARVALHO, José Murilo de; NEVES, Lúcia Maria B. P. das (Orgs.). Repensando o Brasil do Oitocentos: cidadania, política e liberdade. Rio de Janeiro: Civilização Brasileira, 2009, p. 71-100.

VERÇOSA. Elcio de Gusmão. Caminhos da Educação em Alagoas: da Colônia aos dias atuais. Maceió: Catavento, 2001a. 
VERÇOSA. Elcio de Gusmão. Cultura e Educação nas Alagoas: história, histórias. Maceió: Scortecci, 2001b.

VIDAL, Diana Gonçalves. Mapas de freqüência a escolas de primeiras letras: fontes para uma história da escolarização e do trabalho docente em São Paulo na primeira metade do século XIX. In: Revista Brasileira de História da Educação. n. 17. Campinas - SP: Autores Associados, maio/ago. 2008, p. 41-67.

VIEIRA, Maria Alveni Barros; SOARES, Norma P. Lopes. A Professora e o Inspetor: disputa de poder no magistério piauiense na década de 1860. In: IV Encontro de Pesquisa em Educação da UFPI - A pesquisa como mediação de práticas socioeducativas, 2006, Teresina. EDUFPI, 2006.

VILELA, Humberto. A Escola Normal de Maceió. Maceió, Publicação da Secretaria de Educação, 1982.

VILLELA, Heloisa de Oliveira Santos. Do artesanato à profissão: representações sobre a institucionalização da formação docente do século XIX. In: STEPHANOU, Maria e BASTOS, M.H.C. (Org.) Histórias e memórias da educação no Brasil - século XIX. Petrópolis, RJ: Vozes, p. 104-115 2005.

XAVIER, Leopoldo Bibiano. Revivendo o Brasil Império. São Paulo: Artpress, 1991.

\section{Fontes}

ALAGOAS, Arquivo Público do Estado de. Ofícios Recebidos, Mapas de Alunos e Relatórios de Instrução Publica. Disponível em: M 08 E05 (1840-1843); M 13 E 05 (1854 1860); M 09 E 05 (1844 - 1849); M10 E 05 (1850-1854); M12 E 05 (1857-1858), M14 E05(1875-1876). Consultas entre 2008 - 2009.

ALBUQUERQUE, Antonio Coelho de Sá; Antonio Coelho de Sá e Albuquerque: Fala, 1856. Recife: Tip. de Santos \& Companhia, 1856. Disponível em: <http:// brazil.crl.edu/bsd/bsd/22/>. Acesso em: 15 abr. 2010.

AMARAL, Angelo Thomaz do: Angelo Thomaz do Amaral: Fala, 1859. Maceió: Typographia Commercial de Moraes \& Costa, 1859. ESPÍNDOLA, Thomaz do Bomfim. Relatório de instrução pública e particular. Maceió: 1866. Disponível em: Arquivo Público do Estado de Alagoas.

FIGUEIREDO, José Bento da Cunha; José Bento da Cunha Figueiredo: Fala, 1851. Maceió, Typ. de J. S. da S. Maia, 1851. Disponível em:

<http://www.crl. edu/brasil/provincial/alagoas>. Acesso em: 10 abr. 2010. 
PASSOS, José Alexandre. Relatório. Maceió: 1858. Disponível em: Arquivo Público do Estado de Alagoas.

TITARA, José Corrêa da Silva. Relatório da Instrução Pública da Província das Alagoas. Maceió: 1854.

TITARA, José Corrêa da Silva. Relatório da Instrução Pública da Província das Alagoas. Maceió: 1856.

\section{DIÁRIOS:}

DIÁRIO DAS ALAGOAS. Maceió, ano II, nº. 272, 28 nov. 1859. DIÁRIO DAS ALAGOAS. Maceió, ano II, nº. 285, 14 dez. 1859. DIÁRIO DAS ALAGOAS. Maceió, ano XII, 6 de abril de 1870. 